\title{
A prospective controlled study to evaluate a residential community reintegration for patients with chronic acquired brain injury.
}

Citation for published version (APA):

Geurtsen, G. J., van Heugten, C. M., Martina, J. D., Rietveld, A. C., Meijer, R., \& Geurts, A. C. (2011). A prospective controlled study to evaluate a residential community reintegration for patients with chronic acquired brain injury. Archives of Physical Medicine and Rehabilitation, 92(5), 696-704. https://doi.org/10.1016/j.apmr.2010.12.022

Document status and date:

Published: 01/01/2011

DOI:

10.1016/j.apmr.2010.12.022

Document Version:

Publisher's PDF, also known as Version of record

\section{Document license:}

Taverne

Please check the document version of this publication:

- A submitted manuscript is the version of the article upon submission and before peer-review. There can be important differences between the submitted version and the official published version of record.

People interested in the research are advised to contact the author for the final version of the publication, or visit the DOI to the publisher's website.

- The final author version and the galley proof are versions of the publication after peer review.

- The final published version features the final layout of the paper including the volume, issue and page numbers.

Link to publication

\footnotetext{
General rights rights.

- You may freely distribute the URL identifying the publication in the public portal. please follow below link for the End User Agreement:

www.umlib.nl/taverne-license

Take down policy

If you believe that this document breaches copyright please contact us at:

repository@maastrichtuniversity.nl

providing details and we will investigate your claim.
}

Copyright and moral rights for the publications made accessible in the public portal are retained by the authors and/or other copyright owners and it is a condition of accessing publications that users recognise and abide by the legal requirements associated with these

- Users may download and print one copy of any publication from the public portal for the purpose of private study or research.

- You may not further distribute the material or use it for any profit-making activity or commercial gain

If the publication is distributed under the terms of Article 25fa of the Dutch Copyright Act, indicated by the "Taverne" license above, 


\title{
A Prospective Study to Evaluate a Residential Community Reintegration Program for Patients With Chronic Acquired Brain Injury
}

\author{
Gert J. Geurtsen, MSc, Caroline M. van Heugten, MSc, PhD, Juan D. Martina, MD, \\ Antonius C. Rietveld, MSc, PhD, Ron Meijer, MD, PhD, Alexander C. Geurts, MD, PhD
}

ABSTRACT. Geurtsen GJ, van Heugten CM, Martina JD, Rietveld AC, Meijer R, Geurts AC. A prospective study to evaluate a residential community reintegration program for patients with chronic acquired brain injury. Arch Phys Med Rehabil 2011;92:696-704.

Objective: To examine the effects of a residential community reintegration program on independent living, societal participation, emotional well-being, and quality of life in patients with chronic acquired brain injury and psychosocial problems hampering societal participation.

Design: A prospective cohort study with a 3-month waiting list control period and 1-year follow up.

Setting: A tertiary rehabilitation center for acquired brain injury.

Participants: Patients $(\mathrm{N}=70)$ with acquired brain injury (46 men; mean age, $25.1 \mathrm{y}$; mean time postonset, $5.2 \mathrm{y}$; at follow up $n=67)$.

Intervention: A structured residential treatment program was offered directed at improving independence in domestic life, work, leisure time, and social interactions.

Main Outcome Measures: Community Integration Questionnaire (CIQ), Employability Rating Scale, living situation, school, work situation, work hours, Center for Epidemiological Studies Depression Scale, EuroQOL quality of life scale (2 scales), World Health Organization Quality of Life Scale Abbreviated (WHOQOL-BREF; 5 scales), and the Global Assessment of Functioning (GAF) scale.

Results: There was an overall significant time effect for all outcome measures (multiple analysis of variance $\mathrm{T}^{2}=26.16$;

From the Department for Acquired Brain Injury, Rehabilitation Medical Center Groot Klimmendaal, Arnhem (Geurtsen, Martina, Meijer); Department of Psychiatry and Neuropsychology, School for Mental Health and Neuroscience (Heugten) and the Department of Neuropsychology and Psychopharmacology, Maastricht University, Maastricht (Heugten); Department of Rehabilitation, Nijmegen Center for Evidence Based Practice, Radboud University Nijmegen Medical Center, Nijmegen (Meijer, Geurts); St. Maartenskliniek Research Development and Education, Nijmegen (Rietveld, Meijer, Geurts); and Department of Linguistics, Radboud University, Nijmegen (Rietveld), The Netherlands

Presented to the International Society of Physical and Rehabilitation Medicine World Congress, June 13-17, 2009, Istanbul, Turkey; the Satellite Symposium on Neuropsychological Rehabilitation International Neuropsychological Society/World Federation for NeuroRehabilitation special interest group, August 3-4, 2009, Tallinn, Estonia; and the World Federation for NeuroRehabilitation World Congress of Neurorehabilitation, March 22-23, 2010, Vienna, Austria.

Supported by the Johanna Child Fund and BIO Child Rehabilitation Fund (grant no. 2003/0120-009).

No commercial party having a direct financial interest in the results of the research supporting this article has or will confer a benefit on the authors or on any organization with which the authors are associated.

Correspondence to Gert J. Geurtsen, MSc, Rehabilitation Medical Center Groot Klimmendaal, Dept of Acquired Brain Injury, PO Box 9044, 6800 GG Arnhem, The Netherlands, e-mail: Herendubbel@yahoo.com. Reprints are not available from the author.

0003-9993/11/9205-00819\$36.00/0

doi:10.1016/j.apmr.2010.12.022
$\left.\mathrm{F}_{36,557} 134.9 ; P=.000\right)$. There was no spontaneous recovery during the waiting-list period. The effect sizes for the CIQ, Employability Rating Scale, work hours, and GAF were large (partial $\eta^{2}=0.25,0.35,0.22$, and 0.72 , respectively). The effect sizes were moderate for 7 of the 8 emotional well-being and quality of life (sub)scales (partial $\eta^{2}=0.11-0.20$ ). The WHOQOL-BREF environment subscale showed a small effect size (partial $\eta^{2}=0.05$ ). Living independently rose from $25.4 \%$ before treatment to $72.4 \%$ after treatment and was still $65.7 \%$ at follow up.

Conclusions: This study shows that a residential community reintegration program leads to significant and relevant improvements of independent living, societal participation, emotional well-being, and quality of life in patients with chronic acquired brain injury and psychosocial problems hampering societal participation.

Key Words: Brain injuries; Employment; Quality of life; Rehabilitation Residential treatment; Treatment outcome.

(C) 2011 by the American Congress of Rehabilitation Medicine

$\mathbf{A}$ CQUIRED BRAIN INJURY is a significant health problem, which often has considerable consequences for societal participation of those affected. ${ }^{1}$ Specifically, patients with severe psychosocial problems may experience difficulties with community reintegration. Major adjustment issues, as well as problems in transitional periods of living and work situation are frequent and can lead to reduced emotional well-being, depression, ${ }^{2,3}$ and decreased QOL. ${ }^{4}$ Although employment usually is a predictor of well-being, social integration, and QOL, ${ }^{5-8}$ too many work hours combined with serious challenges in the home situation can also lead to an emotional overload. ${ }^{9}$ Hence, the main target for community reintegration programs is to

List of Abbreviations

$\begin{array}{ll}\text { ANOVA } & \begin{array}{l}\text { analysis of variance } \\ \text { CES-D }\end{array} \\ \text { Center for Epidemiological Studies } \\ \text { Depression Scale } \\ \text { Community Integration Questionnaire } \\ \text { EQ-5D } & \begin{array}{l}\text { EuroQOL quality of life scale } \\ \text { GAF }\end{array} \\ & \text { Global Assessment of Functioning } \\ \text { GCS } & \text { scale } \\ \text { MANOVA } & \text { Glasgow Coma Scale } \\ \text { QOL } & \text { multiple analysis of variance } \\ \text { RCT } & \text { quality of life } \\ \text { t } & \text { randomized controlled trial } \\ \text { TBI } & \text { time measurement moments } \\ \text { WHOQOL-BREF } & \text { traumatic brain injury } \\ & \text { World Health Organization Quality of } \\ & \text { Life Scale Abbreviated }\end{array}$


achieve well-balanced improvements in the domains of independent living, employment, emotional well-being, and QOL. ${ }^{10,11}$

Most studies on community reintegration have focused on the subacute phase (ie, $<1 \mathrm{y})$ after injury (eg, Cope et $\mathrm{al}^{12}$ ). In their meta-analytic review, Rohling et $\mathrm{al}^{13}$ found little evidence for the effectiveness of such comprehensive rehabilitation programs when controlling for effect modifiers. Relatively little is known about the effectiveness of community reintegration programs in the chronic phase (ie, $>1 y$ ) after injury. In a recent systematic review, ${ }^{14}$ only 3 studies of minimal methodologic quality were identified concerning chronic acquired brain injury patients. Willer et al ${ }^{15}$ offered a goal-directed intervention in a structured social residential environment based on neurobehavioral principles. They treated 23 chronic patients that were compared with a matched sample of 23 patients receiving limited home-based services. The precise content and intensity of the interventions were not specified. In addition, as acknowledged by the authors, there was no randomized assignment to treatment or control group. Moreover, data of the control group were collected only through the caregivers. Gray and Burnham ${ }^{16}$ conducted a historic cohort study using a database of 349 low-functioning chronic brain injury patients, who did not classify for regular rehabilitation. The patients had been offered a multidisciplinary intervention, of which the content was not specified. Admission and discharge data were reported, but no follow-up data were available. Geurtsen et $\mathrm{al}^{11}$ performed a prospective cohort study of 24 brain injured patients with social, emotional, and vocational integration problems. Patients were treated in a residential community reintegration program consisting of 3 modules: independent living, social-emotional, and work. Admission and discharge data were presented with a follow up of 1 year. However, as in the study by Gray and Burnham, ${ }^{16}$ there was no control of spontaneous recovery or functional change in time. Hence, although all 3 studies reported functional improvements in various domains of community integration, employability, living situation, QOL, and emotional well-being. The level of evidence provided by each of these studies was considered low.

In this context, the present prospective cohort study aimed to establish the effectiveness of the Dutch community reintegration program (Brain Integration Program) ${ }^{11}$ using a 3-month waiting list control period. The waiting list was used to support the notion that treatment effects would not be attributable to spontaneous recovery. We hypothesized that no change would occur during the waiting list period, that significant improvements in the domains of independent living, societal participation, emotional well-being, and QOL would be present directly after the treatment, and that these improvements would be maintained at 1-year follow up.

\section{METHODS}

\section{Participants}

All patients who had been referred for treatment to the Brain Integration Program between August 2003 and February 2007 were eligible for the study. Patients were selected by means of a semi-structured interview which was performed by a physiatrist and a neuropsychologist during which inclusion and exclusion criteria were tested. ${ }^{11}$ Inclusion criteria were: (1) having sustained acquired brain injury (trauma, stroke, tumor, encephalitis, or hypoxia) at least 6 months ago, proven by computed tomography or magnetic resonance imaging; (2) having problems in social functioning, emotional control, and work integration leading to a GAF score ${ }^{17}$ less than 65; and (3) being 18 years or older. Exclusion criteria were: (1) suitability for other outpatient cognitive rehabilitation programs; (2) se- vere disruptive behavior posing danger to other patients or staff; (3) complete lack of problem awareness leading to lack of willingness to change; (4) severe memory problems leading to absent or severely limited ability to store new information; and (5) severe drug addiction or, in case of mild drug addiction, unwillingness to stop drug abuse.

The treatment took place in a tertiary rehabilitation center for acquired brain injury. Rehabilitation centers all over The Netherlands offering regular postacute care (comprehensive day treatment or other outpatient cognitive rehabilitation programs) referred patients who required more intensive guidance and rehabilitation due to an abundance of psychosocial problems hampering societal participation, often accompanied by behavioral problems. Although several patients lived independently, this was unsuccessful which often was an important reason for referral. The Brain Integration Program is a nationally recognized program covered by all health care insurance companies in The Netherlands. ${ }^{18}$

All patients gave oral and written informed consent according to the Helsinki Declaration. ${ }^{19}$ The study was approved by the regional medical ethics committee.

\section{Intervention}

The Brain Integration Program aims at optimal community integration. The essence of the program is that patients learn to establish a balance in their daily activities between domestic life, school and/or work, leisure time, and social interactions, taking into account their individual capacities and limitations. ${ }^{20}$ An optimal balance is considered to be present when patients integrate all these activities and are still able to surmount unexpected problems. When necessary, this should be accomplished in an adjusted living environment with proper paid attendant care. The Brain Integration Program is provided in a residential setting within a specialized rehabilitation center for acquired brain injury. It is offered partly in small groups (about $10 \%$ of time), but mostly as individual therapy (about $90 \%$ of time). After patients are discharged from the program, no follow-up support is given. The treatment program, which has been described more extensively in a previous publication, ${ }^{11}$ consists of 3 modules.

The independent living module aims at training relevant and specific housekeeping abilities. In a structured environment, the patient learns to perform the necessary abilities step-by-step and then learns to plan and execute all these tasks together in his/her domestic life. The average amount of therapy time spent in this module is estimated at 100 hours per person.

The social-emotional module aims at setting new, adjusted, and achievable goals in life. It encompasses education about brain injury and its functional consequences. Coping strategies are trained and individual counseling is provided to reach a higher level of acceptance. Furthermore, social skills are practiced to establish and maintain social interactions. The average amount of therapy time spent in this module is estimated at 110 hours per person.

The vocational module deals with work and leisure time. In a vocational assessment unit, the work tasks that the patient can perform are determined, as well as the amount of hours he/she can work per week, the necessary adjustments to the workplace, and the personal assistance needed. ${ }^{21}$ If independent paid work is not achievable, alternative possibilities are explored (eg, supported or sheltered paid work, volunteer work, or sheltered activities). The average amount of therapy in this module is estimated at about 44 hours per person.

The professional staff for all modules consists of a neuropsychologist, a physiatrist, a psychiatrist, occupational therapists, cognitive therapists, social workers, speech-language 
therapists, physical therapists, and rehabilitation nurses. The therapists registered the intervention time, which did not include the guidance and training by rehabilitation nurses. The latter intervention time was roughly estimated to be 1.5 hours per person per day.

\section{Design}

We conducted a prospective cohort study with a 3-month waiting list control period and a 1-year follow up. Outcome assessments were performed at inclusion (t0), at the start of the treatment 3 months later (t1), at the end of the treatment ( $\mathrm{t} 2)$, and at follow up 1-year after finishing the program (t3)

\section{Outcome Measures}

For societal participation 2 primary measures were used.

Community Integration Questionnaire. ${ }^{22}$ The CIQ is a 15-item self-report questionnaire consisting of 3 subscales (home integration, social integration, and productivity). The total score is used for evaluation and ranges from 0 to 29 . A higher score represents a higher level of integration. The reliability and validity of the CIQ have been established by previous research. ${ }^{23}$

Employability Rating Scale. ${ }^{24}$ The Employability Rating Scale is a 1-item scale with 10 mutually exclusive categories describing the level of employability (eg, paid, supported, sheltered). The score ranges from 1 to 10 . A higher score indicates a higher level of employability. The Employability Rating Scale was developed for brain injury ${ }^{24}$ and has been used in several brain injury studies (eg, Satz et $\mathrm{al}^{25}$ ).

In addition to these primary outcomes, the following measures were used as secondary outcomes.

Living Situation. The living situation is scored on a 1-item scale describing the actual living situation, including the amount of care based on the national standard of the health care indication organization. The scale consists of 12 mutually exclusive categories: (1) living with parents; (2) residential psychiatric hospital; (3) nursing home; (4) community home (24h care); (5) intense home training toward independent living (16-24h coaching/supervision); (6) supported independent living. (12-16h coaching/supervision); (7) supervised independent living (9-12h coaching); (8) supervised independent living (4-9h coaching); (9) living with partner and/or children; (10) living with others; (11) supervised independent living ( $0-4 \mathrm{~h}$ coaching); and (12) living independently without care. Categories 5 through 12 were defined as living independently, whereas categories 1 through 4 were defined as not living independently.

School Situation. This dichotomous measure indicates whether patients are attending school.

Work Situation. This dichotomous measure reflects whether patients have a paid job.

Work hours per week. Rates the amount of hours per week the patient is working.

For the domains of emotional well-being and QOL the following outcomes measures were used.

Center for Epidemiological Studies-Depression Scale. ${ }^{26}$ Emotional well-being was assessed using the 20-item self-report CES-D. The score ranges from 0 to 60 with higher scores representing higher levels of depression. Epidemiologic studies found a cut-off score of 16 or higher for being at risk of depression. ${ }^{27}$ According to Seel et al, ${ }^{28}$ the CES-D has a very good sensitivity but a low specificity in patients with TBI, indicating that it can be used to exclude major depression.

EuroQOL. $^{29}$ QOL was assessed with the EuroQOL, which is a self-report health-related quality of life scale containing a questionnaire with 5 items (EQ-5D) and a Health Status visual analog scale. The score on the EQ-5D ranges from 5 to 15 with lower scores indicating higher QOL. The score on the EuroQOL Health Status visual analog scale ranges from 0 to 100 with higher scores representing a better health status.

World Health Organization Quality of Life Scale Abbreviated. ${ }^{30}$ The WHOQOL-BREF is a 26-item selfreport questionnaire, containing 2 items for overall QOL and general health that are combined into 1 overall score. The other 24 items are categorized into 4 domain scores: physical capacity, psychological well-being, social relationships, and environment. The overall score and the 4 domain scores were used in the analyses. The scores range from 4 to 20 with higher scores indicating higher QOL. The reliability and validity of the WHOQOL-BREF have been established by previous research. ${ }^{31}$

Global Assessment of Functioning Scale of the Diagnostic and Statistical Manual of Mental Disorders $\boldsymbol{I V} .^{17}$ The GAF was used as a clinician's judgment of the patient's overall level of functioning with a range from 0 to 100. A higher score represents a higher level of functioning.

\section{Procedure}

At t0, demographic and clinical data, such as sex, age, date of injury, etiology, coma duration, and lowest initial score on the $\mathrm{GCS}^{32}(<24 \mathrm{~h}$ after trauma/onset; determined by an acutecare paramedic) were collected. The cognitive status of patients was assessed by well-accepted and validated neuropsychologic tests at t1: Test of Sustained Selective Attention, ${ }^{33}$ Trail-Making Test,${ }^{34}$ Stroop Color-Word Test, ${ }^{35}$ Rey Verbal Learning Test, ${ }^{36}$ Story Telling, ${ }^{37}$ Tower of London (a computerized version), ${ }^{38}$ and the Wisconsin Card Sorting Test. ${ }^{39}$ All neuropsychologic tests were performed by an independent test assistant at the rehabilitation center in a quiet room according to the respective test manuals. The CIQ, CES-D, EuroQOL, and WHOQOL-BREF were self-completed by the patients in the rehabilitation center at $\mathrm{t} 0, \mathrm{t} 1$, and $\mathrm{t} 2$ (with an independent test assistant present to assist if necessary). At t3, the CIQ, CES-D, EuroQOL, and WHOQOL-BREF were filled in by the patients at home and returned by mail. The same independent test assistant scored the Employability Rating Scale, living situation, school situation, work situation, and work hours per week in a face-to-face interview at $\mathrm{t} 0, \mathrm{t} 1$, and $\mathrm{t} 2$, and by a telephone interview at $\mathrm{t} 3$. At $\mathrm{t} 0$ and $\mathrm{t} 1$, scales were scored describing the situation before the assessment. At $\mathrm{t} 2$ and $\mathrm{t} 3$, the actual situation at that moment was described. At all instances, patients were asked to disregard any holidays from their descriptions of living and work situation. The GAF scale was scored by the same neuropsychologist at all assessments describing the level of functioning at that moment.

\section{Statistical Analyses}

The characteristics of the patients and the treatment program are presented using descriptive statistics. For the neuropsychologic test scores, means and percentiles were determined. Individual patient scores were considered impaired when they were equal to or lower than the 10th percentile based on existing norm scores from the test manuals or test publications. For the neuropsychologic tests and the outcome measures, we examined whether there was a baseline difference between the patients with a time postonset less than 1 year and the patients with a time postonset more than 1 year using between-subjects MANOVA (with brain injury less or more than 1y as covariate).

A MANOVA with time as a within-subjects factor was done on all nondichotomous outcome measures together (CIQ, Em- 


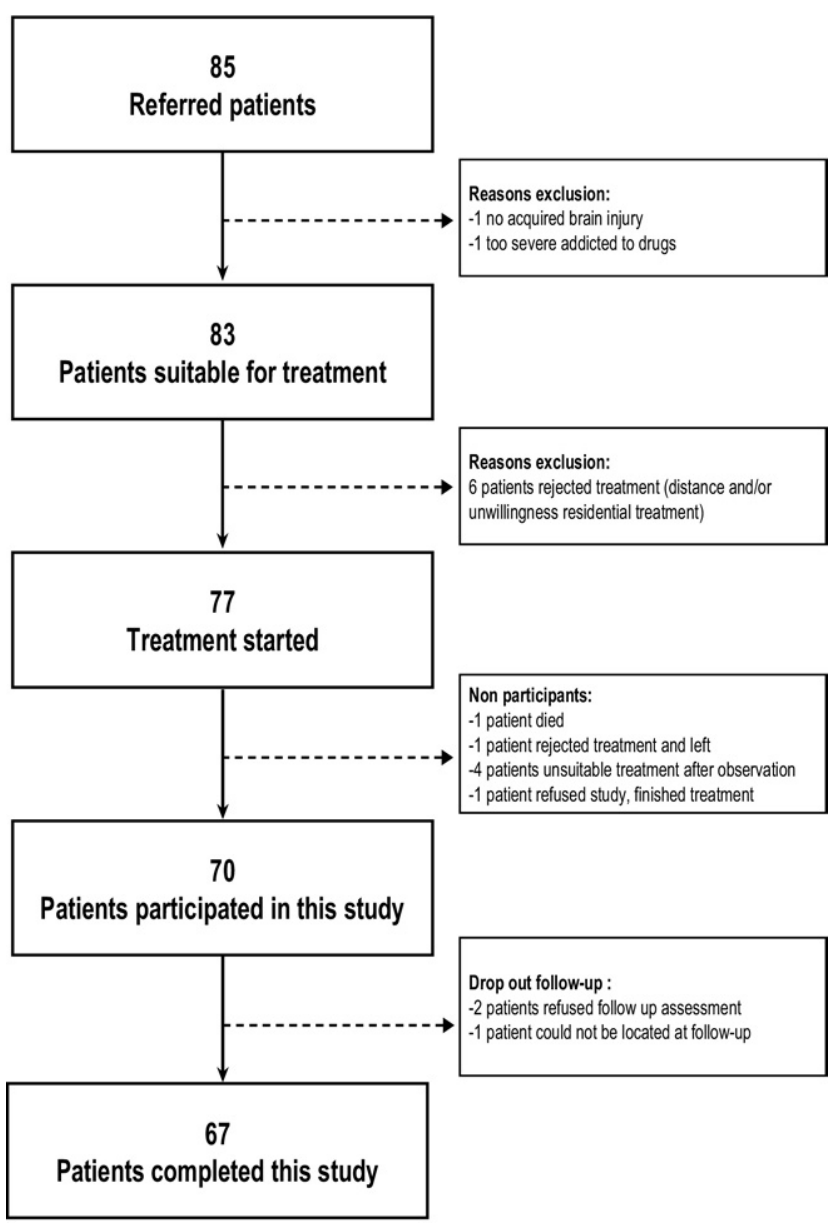

Fig 1. Flowchart of patient inclusion.

ployability Rating Scale, work hours per week, CES-D, EQ-5D, EuroQOL Health Status visual analog scale score, 5 WHOQOL-BREF subscales, and GAF) to assess whether there was an overall time effect. To determine the effects on each specific outcome measure, we used ANOVA for within-subjects time effects with Sidak adjustments for post hoc comparisons. Furthermore, the effect sizes were calculated using partial eta squared values. The partial eta squared value was considered small when ranging from 0.05 to 0.1 , moderate when between 0.1 and 0.2 , and large when greater than $0.2 .^{40}$ Next, we performed a pair-wise ANOVA on each outcome measure to determine in what time period significant changes occurred. A Holm procedure was used to correct for multiple outcomes in all ANOVAs. The 2 dichotomous dependent variables work situation and school situation, both being categorical variables with 2 outcomes: change or no change, were analyzed with logistic regression, with time as the independent variable.

Alpha was set at 0.05 for statistical significance and $P$ values were Huynh-Feldt corrected where appropriate. All analyses were performed with SPSS16.

\section{RESULTS}

\section{Patients and Intervention}

Eighty-five patients were referred for treatment of which 70 were included in the study. In figure 1 , the inclusion process is illustrated. At follow up, data were available for 67 (95.7\%) of the 70 patients.

The patients had sustained a TBI $(67.1 \% ; n=47)$, stroke $(10 \% ; n=7)$, brain tumor $(14.3 \% ; n=10)$, encephalitis $(5.7 \%$; $n=4)$, or hypoxia $(2.9 \% ; n=2)$. Forty-six patients were men $(65.7 \%)$. Subjects had a mean age of $25.1 \pm 7.9$ years (range, $18-49 y)$. The mean time after brain injury was $5.2 \pm 5.4$ years (range, 0.5-26.3y). Of the patients with TBI, $80 \%$ had sustained a severe injury (lowest initial GCS 3-8) and 20\% had a mild injury (lowest initial GCS 13-15); however, always with concomitant computed tomography or magnetic resonance imaging abnormalities, indicating that no patient merely suffered from cerebral concussion. The patient characteristics are shown in table 1 . There were no significant differences between the patients with a time postonset less than 1 year $(n=12)$ and those with a time postonset more than 1 year $(n=58)$ on the neuropsychologic tests and outcome measures. Therefore, the data of all patients are presented and analyzed together.

The cognitive profile of the patients is shown in table 2 . As can be concluded from the percentage of patients in the impaired range of functioning, $50 \%$ of the patients had a deficit in the speed of information processing (Test of Sustained Selective Attention Speed effect) and $17 \%$ to $36 \%$ had an attention deficit (sustained, selective, or divided attention; Test of Sustained Selective Attention, Stroop Color-Word Test, Trail Making Test). In addition, some patients showed executive deficits (Tower of London, Wisconsin Card Sorting Test). Memory deficits (Rey Verbal Learning Test, Story telling) were much less frequent.

The mean duration \pm SD of the Brain Integration Program was $196.2 \pm 61.9$ days (range, $44-357 d$; median $=199 d$ ).

\section{Outcomes}

The means \pm SDs of the outcome measures at $t 0$ through $\mathrm{t} 3$ are displayed in table 3 for the 67 patients that completed all assessments. MANOVA showed an overall significant effect of time for all outcome measures together (MANOVA $\mathrm{T}^{2}=26.16$, $\left.\mathrm{F}_{36,557} 134.9 ; P=.000\right)$. In addition, ANOVA showed significant time effects for each individual outcome measure (table 4). The effect sizes for the CIQ, the Employability Rating Scale, the GAF and the work hours were large (partial $\eta^{2}=0.25,0.35,0.72$, and 0.22 , respectively). The effect sizes were moderate for 7 of the 8 outcome measures concerning emotional well-being and QOL (CES-D, EQ-5D, EuroQOL Health Status visual analog scale score, WHOQOL-BREF overall, physical psychological, social) ranging from 0.11 to 0.20 . The effect size for the WHOQOL-BREF environment was small (partial $\eta^{2}=0.05$ ) (table 5). The effect sizes for

Table 1: Patient Characteristics at Inclusion $(n=70)$

\begin{tabular}{lcc}
\hline \multicolumn{1}{c}{ Characteristics } & Mean \pm SD or $\mathrm{n}(\%)$ & Range \\
\hline Age at admission (y) & $25.1 \pm 7.9$ & $18-49$ \\
Time since onset $(\mathrm{y})$ & $5.2 \pm 5.4$ & $.5-26.3$ \\
Coma score TBI patients (lowest & & \\
$\quad$ GCS within 24h: $\mathrm{n}=16$ ) & $7.5 \pm 4.5$ & $3-15$ \\
Coma duration* (d) & $23.1 \pm 30.2$ & $.5-135$ \\
Living independently at t0 & $19(27.1)$ & \\
School at t0 & $14(20)$ & \\
Patients at work at t0 & $12(17.1)$ & \\
Work hours at t0 (per wk; mean \\
of all patients)
\end{tabular}

*Only TBI patients. 
Table 2: Cognitive Profile of Patients at Start of Treatment $(n=70)$

\begin{tabular}{lcc}
\hline \multicolumn{1}{c}{ Test } & Mean Score \pm SD & \% Patients Impaired \\
\hline TOSSA CS & $67.8 \pm 24.1$ & 57.8 \\
TOSSA Speed effect on CS (score) & $-25.5 \pm 17.5$ & 50.0 \\
TOSSA Sustained attention effect on CS (score) & $-5.4 \pm 23.2$ & 35.9 \\
TMT part A (s) & $47.1 \pm 29.7$ & 50.0 \\
TMT part B (s) & $112.5 \pm 96.2$ & 42.6 \\
STROOP card 1 (s) & $57.6 \pm 19.0$ & 56.7 \\
STROOP card 2 (s) & $74.1 \pm 23.9$ & 47.8 \\
STROOP card 3 (s) & $114.9 \pm 39.5$ & 28.8 \\
STROOP Interference (s) & $44.1 \pm 26.6$ & 16.7 \\
REY VLT immediate recall (total score) & $40.9 \pm 122$ & 29.0 \\
REY VLT delayed recall (no.) & $7.4 \pm 4.80$ & 34.8 \\
Story telling immediate recall (no.) & $14.2 \pm 4.20$ & 24.6 \\
Story telling delayed recall (no.) & $12.6 \pm 5.00$ & 37.7 \\
Tower of London (score) & $76.6 \pm 13.5$ & 9.0 \\
Wisconsin Card categories (no.) & $4.8 \pm 1.90$ & 32.4 \\
Wisconsin Card perseverative errors (no.) & $17.9 \pm 17.1$ & 33.0
\end{tabular}

Abbreviations: CS, Concentration Score; REY VLT, Rey Verbal Learning Test; STROOP, Stroop Color-Word Test; TMT, Trail Making Test; TOSSA, Test Of Sustained Selective Attention; Wisconsin Card, Wisconsin Card Sorting Test.

patients with a time postonset less than 1 year and for those with a time postonset more than 1 year were comparable (see table 5).

Pair-wise ANOVA (table 6) showed that there were no significant changes in the outcome measures during the waiting list period, except for the GAF that showed a slight but significant increase. A stable baseline was present even in the patients $(n=12)$ with a time postonset less than 1 year. Concerning societal participation significant changes were found immediately after treatment for the CIQ and Employability Rating Scale. Logistic regression showed a significant effect of time on work situation (Wald $=23.976, d f=1, P=.000)$. The chance to remain in the same work situation had decreased by about $50 \%$ $(\operatorname{Exp}(B)=.517$, where $\operatorname{Exp}(B)$ is the exponentiation of the $B$ coefficient, which is an odds ratio). There was no effect of time on school situation (Wald $=.020, d f=1, P=.888$, $\operatorname{Exp}(B)=.981)$. After treatment $72.4 \%$ of the patients were living independently compared to $25.4 \%$ before treatment.
As for work hours, there was a positive trend in the expected direction, but no significant change was observed immediately after treatment. Yet, the number of patients working at follow up was $36(53.7 \%)$ out of 67 compared to $17.9 \%$ before treatment. Work hours per week showed an increase toward 18.8 hours per week on average. Significant and substantial improvements were found after treatment for the CES-D, EQ5D, EuroQOL Health Status visual analog scale score, GAF, and for the WHOQOL-BREF overall. As for the other WHOQOL-BREF subscales (physical, psychological, social, and environment), there were only positive but insignificant trends in the expected direction.

None of the outcome measures showed significant deterioration at follow up compared to posttreatment.

\section{DISCUSSION}

The goal of this prospective cohort study, using a 3-month waiting list control period, was to examine the effectiveness of

Table 3: Scores of Outcome Measures $(n=67)$

\begin{tabular}{lcccc}
\hline \multicolumn{1}{c}{ Outcome } & $\mathrm{t} 0$ & $\mathrm{t} 1$ & $\mathrm{t} 2$ & $\mathrm{t}$ \\
\hline ERS & $2.4 \pm 2.1$ & $3.1 \pm 2.3$ & $4.8 \pm 2.8$ & $5.1 \pm 2.2$ \\
CIO & $13 \pm 4.0$ & $13.8 \pm 4.5$ & $16.4 \pm 4.3$ & $16.8 \pm 4.2$ \\
Living independently & $17(25.4)$ & $20(28.6)$ & $50(72.4)$ & $44(65.7)$ \\
School & $14(21)$ & $11(15.7)$ & $10(14.3)$ & $15(22.4)$ \\
Patients at work & $12(17.9)$ & $11(15.7)$ & $23(32.9)$ & $36(53.7)$ \\
Work hours (only working patients) & $14.3 \pm 10.8$ & $12.9 \pm 16.3$ & $18.1 \pm 11.3$ & $18.8 \pm 11.2$ \\
CES-D & $15.49 \pm 11.0$ & $14.36 \pm 10.7$ & $9.29 \pm 7.0$ & $11.48 \pm 8.9$ \\
CES-D above cut-off* (\%) & 46.3 & 43.3 & 16.4 & 30 \\
EQ-5D & $9.22 \pm 2.0$ & $9.03 \pm 1.7$ & $7.99 \pm 1.7$ & $8.49 \pm 1.7$ \\
EuroOOL health score & $60.60 \pm 18.5$ & $66.81 \pm 17.9$ & $76.63 \pm 12.3$ & $71.33 \pm 17.7$ \\
WHOOOL overall & $12.33 \pm 2.4$ & $13.0 \pm 3.5$ & $14.81 \pm 2.4$ & $14.26 \pm 2.9$ \\
WHOOOL physical & $13.14 \pm 2.7$ & $13.80 \pm 3.1$ & $14.98 \pm 2.3$ & $14.81 \pm 2.8$ \\
WHOOOL psychological & $12.91 \pm 3.0$ & $13.70 \pm 3.1$ & $14.65 \pm 2.5$ & $14.00 \pm 2.5$ \\
WHOQOL social & $12.57 \pm 3.6$ & $13.78 \pm 4.1$ & $14.69 \pm 3.6$ & $14.21 \pm 3.7$ \\
WHOOOL environment & $14.29 \pm 2.6$ & $14.53 \pm 2.8$ & $15.40 \pm 2.1$ & $15.19 \pm 3.4$ \\
GAF & $47.48 \pm 6.9$ & $50.15 \pm 8.4$ & $63.10 \pm 8.8$ & $65.70 \pm 10.1$ \\
\hline
\end{tabular}

NOTE. Values are mean $\pm S D, n(\%)$, or as otherwise indicated.

Abbreviations: ERS, Employability Rating Scale; EuroQOL health score, EuroQOL Health Status visual analog scale.

*Cut-off score $\geq 16$. 
Table 4: ANOVA of Within-Subjects Time Effects

\begin{tabular}{lrcc}
\hline \multicolumn{1}{c}{ Outcome } & \multicolumn{1}{c}{$\mathrm{F}$} & $d f$ & $P$ \\
\hline CIO & 22.30 & $2.8,187.9$ & $.000^{*}$ \\
ERS & 34.90 & $2.8,183.6$ & $.000^{*}$ \\
Work hours per week & 18.40 & $2.5,164.7$ & $.000^{*}$ \\
CES-D & 10.50 & $2.7,180.8$ & $.000^{*}$ \\
EQ-5D & 8.20 & $2.9,192.3$ & $.000^{*}$ \\
EuroOOL health score & 16.80 & $3.0,198.0$ & $.000^{*}$ \\
WHOOOL Overall & 12.30 & $2.9,192.6$ & $.000^{*}$ \\
WHOOOL physical & 11.80 & $2.8,185.0$ & $.000^{*}$ \\
WHOOOL psychological & 7.30 & $2.5,165.8$ & $.000^{*}$ \\
WHOOOL social & 7.49 & $2.9,192.0$ & $.000^{*}$ \\
WHOOOL environment & 3.12 & $2.5,165.6$ & $.036^{*}$ \\
GAF & 166.60 & $2.6,173.8$ & $.000^{*}$ \\
\hline
\end{tabular}

Abbreviations: ERS, Employability Rating Scale; EuroQOL health score, EuroQOL Health Status visual analog scale. ${ }^{*} P<.05$ with Holm's procedure, Huynh-Feldt corrected $P$ values where appropriate.

a residential community reintegration program on the domains of independent living, societal participation, emotional wellbeing, and QOL in patients with chronic acquired brain injury and psychosocial problems hampering societal participation. The results as well as the maintenance of treatment effects at 1 -year follow up confirm the effectiveness reported in an earlier uncontrolled cohort study. ${ }^{11}$ The stability of the outcome measures at the 2 assessments before the intervention supports the notion that the included patients did no longer show spontaneous recovery. This is in accordance with our expectation based on the chronic nature of the brain injury, but appeared to be true even for the 12 patients with a time after brain injury less than 1 year (range, 6mo-1y). Hence, we conclude that the observed effects are most likely attributable to the treatment itself.

With regard to community integration, there was a significant increase in the CIQ after treatment with a slight further improvement at follow up. This effect is comparable to our previous study. ${ }^{11}$ In a case-control study of a community reintegration program in patients with TBI, ${ }^{15}$ the CIQ was also used, but raw scores after treatment were not reported. In this latter study, the CIQ score was 10.9 before treatment and appeared to be just below 14 after treatment, as assessed from a graph, which is somewhat lower than in our study. Cicerone et $\mathrm{al}^{41}$ reported an equally low CIQ score (13.2) in a RCT of a holistic neuropsychologic day-treatment program in patients with TBI, although in an earlier study, ${ }^{42}$ they reported CIQ scores comparable to our results. Notably, the significant improvements on the CIQ in the present study were relatively small, yet they were larger than those reported in Cicerone's studies. ${ }^{41,42}$ This seems to be a good result given the fact that we included patients who were not deemed suitable for a regular outpatient rehabilitation program.

Both the employability as assessed with the Employability Rating Scale and the work situation showed a significant increase after treatment. The number of patients working showed an increase from $17.9 \%$ before treatment to $32.9 \%$ after treatment with a further increase up to $53.7 \%$ at follow up. The patients already working showed an increase in the amount of work hours at follow up. The mean number of work hours at follow up was 18.8 , indicating that most of them worked part-time. These results can be regarded as clinically significant considering the figures reported in a recent systematic review on work participation of patients with brain injury. ${ }^{8}$ In this review it appeared that, 2 -years postinjury, only $39.9 \%$ of the patients with non-TBI and $40.7 \%$ of the patients with TBI had returned to work. Fiftythree percent of our patients working at follow up is, therefore, a rather good result, particularly given the selection of patients with psychosocial problems. The increase in the number of working patients as well as the increase in work hours at follow up further support the long-term effectiveness of the Brain Integration Program. This is especially true because no treatment was given after dismissal from the program. Because, at follow up, $22.4 \%$ of the patients were still at school (and some of them will probably have started working after finishing school), the effects on employability may have been even stronger.

After the treatment, the improvement of independent living was substantial, which was followed by a slight further improvement at follow up. The increase toward $65.7 \%$ of the patients living independently can be considered quite satisfactory, although $75 \%$ of the patients who were living independently received some form of (paid) attendant care. ${ }^{21}$

With regard to emotional well-being, there was a significant decrease in the CES-D score after treatment, indicating a lower level of depressive feelings, with merely a slight but insignificant increase at follow up. This effect is comparable to that found in a previous uncontrolled study. ${ }^{11}$ The level of emotional well-being increased as well as the number of patients that scored below the cut-off of 16 , that is, not being

Table 5: Partial Eta Squared Values of Within-Subjects Time Effects

\begin{tabular}{lccc}
\hline \multicolumn{1}{c}{ Outcome } & All Patients $(\mathrm{n}=67)$ & $\begin{array}{c}\text { Patients With Time Since Onset }<1 \mathrm{y} \\
(\mathrm{n}=12)\end{array}$ & $\begin{array}{c}\text { Patients With Time Since Onset }>1 \mathrm{y} \\
(\mathrm{n}=58)\end{array}$ \\
\hline CIO & 0.25 & 0.24 & 0.27 \\
ERS & 0.35 & 0.35 & 0.35 \\
Work hours per week & 0.22 & 0.24 & 0.22 \\
CES-D & 0.14 & 0.05 & 0.20 \\
EQ-5D & 0.11 & 0.03 & 0.15 \\
EuroQOL health score & 0.20 & 0.26 & 0.21 \\
WHOQOL overall & 0.16 & 0.10 & 0.18 \\
WHOQOL physical & 0.15 & 0.14 & 0.16 \\
WHOQOL psychological & 0.10 & 0.13 & 0.13 \\
WHOQOL social & 0.10 & 0.03 & 0.17 \\
WHOQOL environment & 0.05 & 0.23 & 0.03 \\
GAF & 0.72 & 0.69 & 0.73 \\
\hline
\end{tabular}

Abbreviations: ERS, Employability Rating Scale; EuroOOL health score, EuroOOL Health Status visual analog scale. 
Table 6: Pair-Wise Post Hoc Comparisons for 3 Time Intervals

\begin{tabular}{|c|c|c|c|c|c|c|}
\hline Outcome & t0-t1 & $P$ & $\mathrm{t} 1-\mathrm{t} 2$ & $P$ & $\mathrm{t} 2-\mathrm{t} 3$ & $P$ \\
\hline $\mathrm{CIO}$ & -0.81 & 1.000 & -2.60 & $0.000 *$ & -0.42 & 1.000 \\
\hline ERS & -0.70 & 0.936 & -1.72 & $0.000 *$ & -0.30 & 1.000 \\
\hline Work hours per week & 0.35 & 1.000 & -3.65 & 0.072 & -4.49 & 0.087 \\
\hline CES-D & 1.50 & 1.000 & 5.05 & $0.000 *$ & -2.30 & 0.853 \\
\hline EQ-5D & 0.20 & 1.000 & 1.05 & $0.008 *$ & -0.51 & 0.853 \\
\hline EuroQOL health & -6.21 & 0.803 & -9.82 & $0.000 *$ & 5.29 & 0.853 \\
\hline WHOQOL overall & -0.75 & 1.000 & -1.73 & $0.008 *$ & 0.54 & 0.969 \\
\hline WHOQOL physical & -0.65 & 1.000 & -1.18 & 0.072 & 0.17 & 1.000 \\
\hline WHOQOL psychological & -.079 & 0.803 & -0.96 & 0.246 & 0.66 & 0.949 \\
\hline WHOQOL social & -1.22 & 0.528 & -0.90 & 0.246 & 0.47 & 1.000 \\
\hline WHOQOL environment & -0.24 & 1.000 & -0.86 & 0.246 & 0.21 & 1.000 \\
\hline GAF & -2.67 & $0.026 *$ & -12.96 & $0.000 *$ & -2.60 & 0.686 \\
\hline
\end{tabular}

* $P<.05$ with Sidak adjustment and Holm procedure.

Abbreviations: ERS, Employability Rating Scale; EuroQOL health score, EuroQOL Health Status visual analog scale.

at risk of depression. ${ }^{28}$ Although the number of patients scoring 16 or higher decreased substantially from $46.3 \%$ at baseline to $30 \%$ at follow up. This incomplete remission of emotional problems warrants further attention in future studies. As for QOL, there were significant improvements on most scales during the treatment period, except on some of the WHOQOL-BREF subscales (physical, psychological, social, and environment) that merely showed a positive trend. At follow up, no significant change in any QOL measure was present, which is coherent with previous results. ${ }^{11}$ Apparently, the obtained emotional and qualitative benefits from the community reintegration program do not easily subside in the long term, which can probably be understood based on the structural improvements of independent living and societal participation. These improvements indicate clinically relevant changes particularly with regard to living situation, work situation, and emotional well-being of the patients.

It has been argued that a higher level of independent living and societal participation might lead to an excessive emotional burden on patients with chronic brain injury. ${ }^{9}$ However, the observed improvements of emotional wellbeing and QOL indicated that such a trade off did not occur in our study. On the contrary, a good balance was achieved between school, work, and domestic responsibilities, leaving sufficient time for leisure and social activities. At the end of the program, patients appeared to be aware of their limitations and of the necessity to adjust daily activities to their individual abilities.

\section{Study Limitations}

We purposely chose to use a waiting list control period and not to conduct an RCT, which is a methodologic limitation. However, in our systematic review, ${ }^{14}$ we have argued that conducting an RCT may not be feasible in a population of brain injured patients with severe psychosocial and participation problems. It was anticipated that using a waiting list condition of equal length as the treatment period, a sham treatment, or no treatment at all as a control would not be acceptable for the majority of the eligible patients or their caregivers, leading to many of them refusing participation. Using a 3-month waiting list period was considered the most feasible design option to obtain at least some form of within-subjects control, albeit not optimal. An alternative would have been to compare the Brain Integration Program with another existing and realistic intervention, but this option was considered to be premature in the target population of this study, given the lack of clinical evidence in this area. ${ }^{13,14}$ Nevertheless, future studies should attempt to apply more rigorous types of within- or between-subjects control.

Surprisingly, 20\% of the patients with TBI in this study had sustained mild brain injury according to their initial GCS score. Yet, all of them showed computed tomography or magnetic resonance imaging abnormalities during further investigation, indicating that they did not merely suffer from cerebral concussion. The fact that they also had persistent psychosocial problems supports the notion that the severity of their brain injury was more severe than was estimated based on the GCS. This finding suggests that the initial GCS score may underestimate the severity of injury in some patients. Indeed, it is well known that the GCS score may sometimes deteriorate in the early days after brain injury, ${ }^{43}$ which limits the predictive value of the lowest initial $(<24 \mathrm{~h})$ GCS score.

We did not systematically record the behavioral abnormalities of the individual patients before and after treatment due to the lack of a comprehensive instrument to assess all behavioral problems. ${ }^{44}$ In future studies, some form of assessment of behavioral problems should, nonetheless, be considered. Another limitation is that the GAF, which is a clinician-administered scale, was not recorded blind. As a consequence, its effect size may have been relatively large.

The fact that we studied the effect of an intensive (and thus expensive) treatment program, which might be hard to implement in many countries, may also be considered a limitation. Yet, we believe that the costs of residential community integration programs for brain injured patients with societal participation problems are lower than the societal costs (eg, health care costs, informal care costs, and productivity losses) that these patients would create when they would not be treated, especially given their relatively young age. Therefore, future studies should also focus on the socioeconomic benefits of residential community reintegration programs in these patients.

\section{CONCLUSIONS}

Until now, this is the largest prospective study of a residential community reintegration program for patients with chronic acquired brain injury using a waiting list control period. It is shown that such a program is an effective 
treatment leading to significant improvements of QOL, emotional well-being, work situation, and independent living in patients with chronic acquired brain injury and severe psychosocial problems hampering societal participation. Treatment effects are maintained at 1-year follow up. The results indicate that the improvements of independent living and societal participation are not achieved at the expense of emotional stability.

Acknowledgements: We thank Ank Loijen, MSc, Naziha Achouitar, MSc, Cathelijne van den Bulck, MSc, Maarten van Raalte, MSc, Mieke van der Haas, MSc, Tobias Coppes, MSc, Petra van Rees, MSc, Inge Siebe, MSc, Ester Bonten, MSc, and Michiel Boudewijn, MSc, for their contribution in collecting the data.

\section{References}

1. Yates PJ. Psychological adjustment, social enablement and community integration following acquired brain injury. Neuropsychol Rehabil 2003;13:291-306.

2. Hesdorffer DC, Rauch SL, Tamminga CA. Long-term psychiatric outcomes following traumatic brain injury: a review of the literature. J Head Trauma Rehabil 2009;24:452-9.

3. Whelan-Goodinson R, Ponsford J, Johnston L, Grant F. Psychiatric disorders following traumatic brain injury: their nature and frequency. J Head Trauma Rehabil 2009;24:324-32.

4. Anderson V, Brown S, Newitt H, Hoile H. Educational, vocational, psychosocial and quality-of-life outcomes for adult survivors of childhood traumatic brain injury. J Head Trauma Rehabil 2009;24:303-12.

5. O'Neill J, Hibbard MR, Brown M, et al. The effect of employment on quality of life and community integration after traumatic brain injury. J. Head Trauma Rehabil 1998;13:68-79.

6. Abrams D, Barker LT, Haffey W, Nelson H. The economics of return to work for survivors of traumatic brain injury: vocational services are worth the investment. J Head Trauma Rehabil 1993; 8:59-76.

7. Wehman P, Targett P, West M, Kregel JE. Productive work and employment for persons with traumatic brain injury: what have we learned after 20 years? J Head Trauma Rehabil 2005;20:115-27.

8. van Velzen JM, van Bennekom CA, Edelaar MJ, Sluiter JK, Frings-Dresen HW. How many people return to work after acquired brain injury: a systematic review. Brain Inj 2009;23: 473-88.

9. Doig E, Fleming J, Tooth L. Patterns of community integration 2-5 years post-discharge from brain injury rehabilitation. Brain Inj 2001;15:747-62.

10. Malec JF, Basford JS. Postacute brain injury rehabilitation. Arch Phys Med Rehabil 1996;77:198-207.

11. Geurtsen GJ, Martina JD, van Heugten CM, Geurts AC. A prospective study to evaluate a new residential community integration programme for severe chronic brain injury: The Brain Integration Programme. Brain Inj 2008;22:545-54.

12. Cope DN, Cole JR, Hall KM, Barkan H. Brain injury: analysis of outcome in post-acute rehabilitation system. Part 1: general analysis. Brain Inj 1991;5:111-25.

13. Rohling ML, Faust ME, Beverly B, Demakis G. Effectiveness of cognitive rehabilitation following acquired brain injury: a metaanalytic re-examination of Cicerone et al.'s $(2000,2005)$ systematic reviews. Neuropsychology 2009;23:20-39.

14. Geurtsen GJ, van Heugten CM, Martina JD, Geurts AC. Comprehensive rehabilitation programmes in the chronic phase after severe brain injury: a systematic review. J Rehabil Med 2010;42: 97-110.

15. Willer B, Button J, Rempel R. Residential and home-based rehabilitation of individuals with traumatic brain injury: a case control study. Arch Phys Med Rehabil 1999;80:399-406.
16. Gray DS, Burnham RS. Preliminary outcome analysis of a long term rehabilitation program for severe acquired brain injury. Arch Phys Med Rehabil 2000;8:1447-56.

17. American Psychiatric Association. Diagnostic and Statistical Manual of Mental Disorders DSM-IV-TR Fourth Edition (Text Revision). Arlington: APA; 2000.

18. Ribbers GM. Traumatic brain injury rehabilitation in the Netherlands: dilemmas and challenges. J Head Trauma Rehabil 2007; 22:234-38.

19. Carlson RV, Boyd KM, Webb DJ. The revision of the Declaration of 3. Helsinki: past, present and future. $\mathrm{Br} \mathrm{J}$ Clin Pharmacol 2004;57:695-713.

20. Mateer CA, Sira CS, O’Connell ME. Putting Humpty Dumpty together again: the importance of integrating cognitive and emotional interventions. J Head Trauma Rehabil 2005;20:62-75.

21. McCluskey A. Paid attendant carers hold important and unexpected roles which contribute to the lives of people with brain injury. Brain Inj 2000;14:943-57.

22. Willer B, Rosenthal M, Kreutzer JS, Gordon WA, Rempel R. Assessment of community integration following rehabilitation for traumatic brain injury. J Head Trauma Rehabil 1993;8:75-87.

23. van Baalen B, Odding E, van Woensel MP, van Kessel MA, Roebroeck ME, Stam HJ. Reliability and sensitivity to change of measurement instruments used in a traumatic brain injury population. Clin Rehabil 2006;20:686-700.

24. Ben-Yishay Y. Silver SM, Piasetsky E, Rattock J. Relationship between employability and vocational outcome after intensive holistic cognitive rehabilitation. J Head Trauma Rehabil 1987;2: 35-48.

25. Satz P, Zaucha DL, Forney DL, et al. Neuropsychological, psychosocial and vocational correlates of the Glasgow Outcome Scale at 6 months post injury: a study of moderate to severe traumatic brain injury patients. Brain Inj 1998;12:555-67.

26. Radloff LS. The CES-D scale: a self-report depression scale for research in the general population. Appl Psychol Meas 1977;1: 385-401.

27. Bouma J, Rancho AV, Sanderman R, Sonderen E van. [Het meten van symptomen van depressie met de CES-D. Een handleiding] [Dutch]. Groningen: Groningen University; 1995.

28. Seel RT, Macciocchi S, Kreutzer JS. Clinical considerations for the diagnosis of major depression after moderate to severe TBI. J Head Trauma Rehabil 2010;25:99-112.

29. Dolan P. Modeling valuations for EuroQol health states. Med Care 1997;35:1095-108

30. World Health Organization. WHOQOL-BREF - Introduction, administration, scoring and generic version of the assessment. Geneva: WHO; 1996.

31. Chiu WT, Huang SJ, Hwang HF, et al. Use of the WHOQOLBREF for evaluating persons with traumatic brain injury. J Neurotrauma 2006;23:1609-20.

32. Teasdale G, Jennet B. Assessment and prognosis of coma after head injury. Acta Neurochir 1976;34:45-55.

33. Kovács F. Test of Sustained Selective Attention manual. Oegstgeest: Pyramid Productions; 2001.

34. Reitan RM. Trail making test: manual for administration and scoring. South Tucson: Reitan Neuropsychological Laboratory; 1992.

35. Stroop JR. Studies of interference in serial verbal reactions. J. Exp Psychol 1935;18:643-62.

36. Rey A. [L'Examen clinique en psychologie] [French]. Paris: Presse Universitaire de France; 1964.

37. Reitan RM, Wolfson D. The Halstead-Reitan neuropsychological test battery: theory and clinical interpretation. Tucson: Neuropsychology Pr; 1985.

38. Kovács F. Tower of London Test manual. Oegstgeest: Pyramid Productions; 2001. 
39. Heaton RK, Chelune GJ, Talley JL, Kay GC, Curtiss G. Wisconsin Card Sorting Test Manual. Revised and expanded. Odessa: Psychological Assessment Resources Inc; 1993.

40. Cohen J. Statistical Power Analysis for the Behavioral Sciences. New York: Academic Pr; 1966.

41. Cicerone KD, Mott T, Azulay J, Sharlow-Galella MA, et al. A randomized controlled trial of holistic neuropsychologic rehabilitation after traumatic brain injury. Arch Phys Med Rehabil 2008; 89:2239-49.

42. Cicerone KD, Mott T, Azulay J, Friel JC. Community integration and satisfaction with functioning after intensive cognitive rehabil- itation for traumatic brain injury. Arch Phys Med Rehabil 2004;85:943-50.

43. Stein SS, Ross SE. Mild head injury: a plea for routine early CT scanning. J Trauma 1992;33:11-3.

44. Velikonja D, Warriner E, Brum C. Profiles of emotional and behavioral sequelae following acquired brain injury: cluster analysis of the Personality Assessment Inventory. J Clin Exp Neuropsych 2010;32:610-21.

\section{Supplier}

a. SPSS Inc, 233 S Wacker Dr, 11th Fl, Chicago, IL 60606. 